\title{
EP-45
}

\section{Laparoscopic and robotic radical surgery for liver alveolar echinococcosis}

\author{
Natalia ELIZAROVA*, Mikhail EFANOV, Ruslan ALIKHANOV, Ivan KAZAKOV, \\ Andrey VANKOVICH, Olga MELEKHINA, Yulia KULEZNEVA, Victor TSVIRKUN
}

Department of Hepatopancreatobiliary Surgery, Loginov Moscow Clinical Scientific Center, Russia

Introduction: The aim of this study was to estimate the immediate and long-term results of laparoscopic and robotic radical surgery for liver alveolar echinococcosis (AE).

Methods: From 2013 to 20196 patients with AE were undergone radically surgery using minimally invasive technologies. In 5 cases, a laparoscopic liver resection was performed, and in one case a Da'Vinci robotic complex was used. The average lesion size was $60 \pm 20 \mathrm{~mm}$. Results: In three cases (50\%) patients with P2 stage of the disease were operated on, in 3 cases with P1. In two cases, in patients with stage P2, a right hemihepatectomy was performed, in 2 cases a segmentectomy 8 with atypical resection segment 4 was performed, in one case a posterior sectionectomy was performed, in one case the intervention was performed with atypical resection of 6 segments. The average age of the patients was 55 years (27-79), three women and three men (1:1). The average size of the lesion was $60 \pm 20 \mathrm{~cm}$. The mean operation time and blood loss was $344 \pm 141$ minutes and $350 \pm 333 \mathrm{~mL}$. Complications were observed in one case (16.7\%), type II according to Clavien-Dindo, represented by dynamic intestinal obstruction, which developed on the 6th day of the postoperative period and was resolved conservatively. Mean hospital stay was $9 \pm 3$.

Conclusions: Laparoscopic and robotic liver resections in the radical treatment of alveococcosis can be safe and feasible in the early stages of alveococcosis (P1-2H0M0), provided they are performed in a specialized hospital with sufficient technical equipment and an experienced surgeon. 